\title{
Development, Implementation and Importance of an Undergraduate Peer Research Consultant Program at the University of North Dakota's Chester Fritz Library
}

\author{
Karlene T. Clark \\ University of North Dakota, karlene.clark@library.und.edu \\ Holly Gabriel \\ University of North Dakota, holly.gabriel@library.und.edu \\ Kristen Borysewicz \\ University of North Dakota, kristen.borysewicz@und.edu
}

\section{How does access to this work benefit you? Let us know!}

Follow this and additional works at: https://commons.und.edu/cfl-lp

Part of the Library and Information Science Commons

\section{Recommended Citation}

Karlene T. Clark, Holly Gabriel, and Kristen Borysewicz. "Development, Implementation and Importance of an Undergraduate Peer Research Consultant Program at the University of North Dakota's Chester Fritz Library" (2020). Librarian Publications. 19.

https://commons.und.edu/cfl-Ip/19

This Article is brought to you for free and open access by the Chester Fritz Library at UND Scholarly Commons. It has been accepted for inclusion in Librarian Publications by an authorized administrator of UND Scholarly Commons. For more information, please contact und.commons@library.und.edu. 


\title{
Development, Implementation and Importance of an Undergraduate Peer Research Consultant Program at the University of North Dakota's Chester Fritz Library
}

\author{
Karlene Tura Clark \\ Karlene.clark@und.edu \\ *Corresponding Author \\ Holly M. Gabriel \\ Holly.gabriel@und.edu \\ Kristen Borysewicz \\ Kristen.borysewicz@und.edu
}

Authors:

All three work at Chester Fritz Library, University of North Dakota, Grand Forks, North Dakota, USA

\begin{abstract}
:
Purpose: This paper describes both the development of a peer research consultant programusing student assistants to staff the reference desk with minimal supervision while providing high quality research assistance to their undergraduate peers, and the steps taken to create buy-in for the program from campus and librarians.
\end{abstract}

Design / methodology / approach: The authors provide a description of peer reference services and describe how a remodel of the library building facilitated a redesign of services. The paper covers the process of developing program guidelines, securing funding, expectations of peer research consultants, the training process, and lessons learned from a medium-sized academic library. 
Findings: The findings after the first year demonstrate that undergraduates are highly skilled at providing high-quality reference services when provided with quality training and support. In addition, undergraduate students are now seeking out peer researchers for assistance with research items such as topic formation, keyword development in databases and proper citations.

Originality / value: This paper draws on multiple iterations of peer reference models to create an original program, involving training student employees to provide reference services at a paraprofessional-level, as well as providing the methodology for other academic libraries to develop and launch a similar program.

Practical Applications: Well-trained Peer Research Consultants (PRCs) provide valued assistance to librarians in freshman composition classes, at the Ask Us reference desk, and to their peers. The program has allowed librarians to provide more outreach to their subject areas.

Social Implications: Students prefer going to their peers for research assistance rather than a professional librarian when given the choice. The training the PRCs are provided by librarians provides credibility and trust, which encourages undergraduate students to approach PRCs for assistance.

Keywords: Peer research, mentoring, reference services, student, undergraduates, academic libraries

Paper type: Methodology - Conceptual 


\section{Introduction}

With the large reduction of patrons asking for the help of the reference librarians at the central reference desk, academic library administrators are challenged with serving patrons in the most cost-effective way, including using paraprofessional staff or student employees to help staff service desks. Despite the turnover rate of library student employees due to graduation, the literature indicates that peer mentoring is a growing trend among institutions of higher education across the United States (O’Kelly, Garrison, Merry, \& Torreano, 2015). The literature also indicates that the merging of separate help desks into single points of service where tiered assistance can be provided (Faix, 2014) is also a trend. After a review of the literature, the Chester Fritz Library (CFL) at the University of North Dakota (UND) created and implemented a Peer Research Consultant (PRC) program to provide reference services to undergraduate students, utilizing other undergraduates as student mentors as well as providing higher level assistance to the reference librarians, such as collaborating with instruction, outreach, and creating online tutorials. There are a variety of names for peer mentors used in academic libraries including peer consultants, research consultants, peer coaches, and Research Assistant Technicians (RATs).

What makes CFL's program unique is that the PRCs are not handling the basic directional questions, but instead taking the first line of consultations. The student working the Information Desk refers the patron to the PRC, who will determine if the question can be answered at that level. If they cannot (such as it being a question for a graduate student) or the consultation goes 
over their time limit due to a question being extremely difficult or very focused, the PRC then passes it on to the subject librarian. UND also does not have a library science program; none of the students in the program are planning to go on to become librarians after attaining their undergraduate degrees.

Renovations and remodeling of CFL were the catalysts to moving to a new model of providing services within the building. There was also interest in developing a single point of service for students that would meet the needs of more than just a simple information desk. While that vision is still being fully developed, the Library introduced a model of peer to peer research that aligns with the university's strategic plans of student engagement, retention, and success. (University of North Dakota, n.d.).

Over the course of one year, the PRC library program went from concept to implementation. The authors of this article discuss the development from research through creation of working documents, to hiring and training student employees. A strong focus includes garnering buy-in from librarians and campus administrators, which allowed for funding the program. The lessons learned that will guide the next steps forward are included so that librarians can implement a similar program, adapting the program as necessary for their campus needs. 


\section{Purpose and Process of the PRC Program}

The Association of College and Research Libraries (ACRL) statistics for libraries in universities with doctorate degrees indicate that across the United States, the number of reference transactions declined from 21.3 million in 2001 to just nine million in 2012 , a drop of $57 \%$

(Bunnett et al., 2016). UND is a public research university with an enrollment of over 13,000 students in 2019. CFL, which is UND's main library on campus, has also seen a steady decline in the number of reference questions over the past ten years. Students often prefer searching for information independently and seek assistance only when frustrated by the amount of time the research is taking (Reiter \& Cole, 2019). CFL leaders realize that for a library to remain a viable academic service, highly trained professionals cannot continue to tie up their time providing a service that is dramatically decreasing in usage. When reference librarians no longer staff a service desk, it frees up their time for higher-level work such as information literacy instruction, collection development, and more in-depth research appointments with students and faculty. At CFL, librarians are able to improve students' access to online chat reference services by subscribing to Springshare LibAnswers with librarians around the world helping to provide 24/7 coverage. During regular library hours, PRCs are also available through chat reference serving students at their point of need.

The process to create and implement a peer mentoring program at CFL evolved over several years. In 2016, Karlene Clark, who had worked at CFL since 2001 as Coordinator of Circulation Services \& Students, completed a research paper during her MLIS program on peer mentors in academic libraries. According to her research, student employee peer mentor tasks in academic 
libraries ranged in level of duty from simply being a point person at an information desk to undergraduates teaching other undergraduates how to conduct research. Clark was impressed with these university programs empowering their student employees to do higher-level duties, as she was already expecting more from her Access Services students than simply shelving materials or checking items out to patrons. She shared her research paper with Stephanie Walker, Dean of Libraries and Sally Dockter, Assistant Director and Head of Public Services, who both share Clark's high expectations for student employees.

In the fall of 2018, while Clark and Walker were examining student employee responsibilities, CFL was also beginning a major renovation of all four floors of the building. Dockter was particularly concerned with improving service points and wayfinding in the library. The renovation project also provided the opportunity to consider alternatives to traditional reference services, as well as to evaluate other academic services which could be provided in the library, such as a "One Stop" location for students' academic services, including writing consultations, career services, and tutoring services. This concept is similar to the "One Stop" location recently created for financial services on campus. Faix (2014, p 307) also noted this as a "natural extension of the information commons service model." The library is working to partner with the University's Writing Center and Career Services peer mentors, for example. These students will work alongside the PRCs in a localized "commons" area.

In February 2019, CFL moved forward in redesigning reference services. Having graduated in December 2018 with her MLIS, Clark's position was rewritten to Coordinator, Peer Research 
Consultant Reference Service Librarian, and she was tasked with creating and implementing the new service. Her literature review had revealed that a best practice for developing a peer mentoring program is to create a team with a supervisor from Access Services (as they generally manage more students with a focus on training and evaluation) (Faix, et al., 2010) and two reference librarians with a background in information literacy instruction to implement the program, taking advantage of staff knowledge from both departments. Holly Gabriel, the supervisor for reference student employees, and Kristen Borysewicz, Research Skills Instruction Coordinator, both from the reference department, joined Clark to implement the program after discussion and approval from Dockter.

The PRC program supports the mission of CFL, which is to inspire learning, teaching, and research excellence by connecting communities, within and beyond the University, to the world's knowledge. Based on the vision and goals of CFL as outlined in the 2018 Strategic Plan (University of North Dakota, n.d.), the team completed a white paper for the Dean of Libraries and the Provost early in 2019. Discussion included goals of the program, services, reasoning, staffing, structure, assessment, budget, and a timeline for implementation. It was proposed that the library, as the academic heart of the university, use the "One Stop" concept to develop a Knowledge Commons, housing the library PRCs and other academic partners to offer students a central location for academic services. This would serve as a place for students to learn and practice critical thinking skills, research and writing skills, and additional academic skills needed for their college career and beyond. The Knowledge Commons also supports and aligns with the University’s goals, including providing a strong undergraduate liberal arts foundation, increasing 
undergraduate graduation rates, and enhancing discovery at a level consistent with most research-intensive universities (“Chester Fritz Library,” 2018).

\section{Construction and Goals of PRC Program}

Clark and Gabriel each completed literature review research projects for their separate graduate classes on the concept of peer mentors in academic libraries. On comparison, they found many similarities that informed the construction and goals of the PRC program. While this paper does not hold a traditional comprehensive literature review, their research is included throughout, showing the foundational strengths they identified to begin constructing the new library service of peer mentoring.

Peer mentoring is defined as "a helping relationship in which two individuals of similar age and/or experience come together, either informally or through formal mentoring schemes in the pursuit of fulfilling some combination of functions that are career-related (e.g. information sharing, career strategizing) and psychosocial (e.g. confirmation, emotional support, personal feedback, friendship" (Bodemer, 2014, p 164). Students report a preference to work with their peers rather than a professional librarian because they feel more comfortable and less intimidated with their peers when asking for assistance (Bandyopadhyay \& Boyd-Byrnes, 2016). In addition, stereotypes affect whether a student perceives a librarian as approachable, including the librarian's personal characteristics and appearance (Reiter \& Cole, 2019). One goal of the peer mentoring program is to make students feel more comfortable in asking for assistance, which 
will hopefully lead to greater confidence in mentees' abilities. In addition, "there is a strong case for integrative services to support students' mental health and academic needs. This points to a shared responsibility across campus units, including counseling and health services, academic departments and academic support services" (Lipson \& Eisenberg, 2018, p. 211).

Research consultations with students are valuable supplements to information literacy instruction despite the required time investment. However, while librarians might be prone to overcomplicating basic instruction, the affective advantages of a peer researcher include selfconfidence and empathy (Bodemer, 2014). Reiter \& Cole (2019) also report that students had decreased anxiety, as well as an increase in library use comfort and research confidence, which could improve student retention and success while counteracting students' negative emotions, such as irritation and frustration. The researchers feel that this alone proved the value and importance in committing personnel time to developing and implementing a program. Helping students develop a sense of belonging on campus is critically important to student success, especially considering increased rates of anxiety and depression in college students. Roughly one-third of students experience significant symptoms of a mental health problem, such as depression, anxiety, or suicidality (Lipson \& Eisenberg, 2018), which is a serious concern for all educators.

Faix (2014) noted that reference student assistants helped in many areas such as how to print, find books on shelves, or search the online catalog. These however were basic tasks already provided by the students working in Access Services. The authors wanted the PRC program at 
CFL to be similar to peer mentoring programs such as those at Pennsylvania State University and Grand Valley State University (GVSU) Library in Michigan. For example, at GVSU undergraduate students provide frontline reference services in their Knowledge Market, where student employees are trained to assist their peers in one-on-one or in small groups by guiding students through a conversation rather than doing the work for students. This interaction typically is in person, with the PRC and student able to engage in conversation, see body language, and share knowledge (O’Kelly et al., 2015).

Peer-to-peer student learning differs fundamentally from the authoritative interaction between a student and a faculty member in the traditional faculty-student hierarchy (O'Kelly et al., 2015) because undergraduate PRCs are student learners themselves, with unique and immediate perspectives on the undergraduate experience. While assisting their peers, the peer consultants explore new ideas, gain new knowledge about a variety of disciplines, and improve their research skills.

UND has utilized peer mentoring programs in several areas such as undergraduate teaching assistants (UTAs). CFL advanced this concept as the PRCs began providing peer mentoring to undergraduate students in library research skills in the fall of 2019, specifically for instruction duties where PRCs became active assistants in composition classes by introducing themselves at the beginning of class and giving a short description of the PRC program. Currently, PRCs help with the hands-on portion of the class by assisting students with refining topics, finding keywords, database searching, and citations. Many times, the PRCs are also asked to 
demonstrate material for a class. They are very active in creating and updating research guides and other resources used for information literacy instruction, as well as developing training tutorials for future PRCs and aiding in basic reference training for the Access Services student employees.

Clark, Gabriel, and Borysewicz identified other possible future duties for the PRCs including assisting with such projects as the campus-wide new student orientation, curriculum mapping, analysis of information literacy instruction assessment data, and library citation management clinics. PRCs are involved in outreach as they share news about the PRC service with their classmates and friends.

The goals of PRC program include:

- Contribute to student learning by leveraging the social advantages of peer learning.

- Enhance the learning and collegiate experience of the students hired by CFL.

- Improve PRC's skills of facilitation, oral communication, problem-solving, customer service, and reference interview techniques in order to develop career readiness.

- Contribute to UND's Strategic Plan by providing high impact practices (HIPs) to the undergraduates working as PRCs.

\section{Funding}

Securing appropriate funding to ensure the PRC's success was a priority in the development of the program. Library leadership requested funding from the university administration to increase student staffing, which was granted. A combination of Federal Work-Study funds and 
institutional funds from the library's budget were used to implement the program. Working an average of 10-12 hours per week, PRCs are classified as level II employees (starting at \$11.10) due to the degree of skills and expertise they are required to have. UND's Provost is a strong advocate for the program and rallied other academic units to support the development of the Knowledge Commons in the library.

\section{Buy-in from Campus Community and Librarians}

It is important that the university administration, faculty, and student body understand the value of the program and how it relates to the university's strategic plan and goals. In addition, there is a strong need to secure buy-in from all library employees including library leadership, reference librarians, staff, and student employees for making effective changes in library services.

For many librarians, an interaction at the reference desk with students is their favorite job responsibility, making it difficult for many to give up that responsibility. Without the reference librarians' buy-in, this kind of organizational change has shown a 70\% failure rate because of unspoken territorial concerns regarding their expertise and value, that only those with their MLIS should staff a reference desk (Evans \& Alire, 2013). There is also a misconception that students are only able to handle low-level tasks, such as shelving materials. Clark was even informed at one point that her students had overheard a librarian say, 'I don't know why we need students out of Access Services. All they know how to do is check out books." Considering the Access Services department already had a history of preparing students for work beyond college with 
challenging projects, these accomplishments need to be shared widely with staff so that they realize students can handle these responsibilities. Other general concerns include students doing professional librarian duties (as opposed to handling easier questions that often fall to staff) and if students would know when to refer appropriate questions to a librarian. Explaining to staff that this service model did not diminish the users' need for a librarian was key. Reinforcing that "any tiered model of reference service actually frees up librarians to focus on helping those patrons who need more specialized or in-depth research assistance" (Faix, 2014, p 307) helped to allay their concerns.

While the authors will continue to monitor current RUSA discussions on the evolution of reference services, such as providing the most effective and efficient services to patrons at their point of need, an article in the Journal of Academic Librarianship (Ryan, 2013) addresses the 2008 RUSA definition of reference services for librarians, stating it "includes reference transactions and other activities that involve the creation, management and assessment of information or research resources, tools, and services.” The article further explains the costeffectiveness for the library by having students trained to handle appropriate questions at the desk, freeing librarians from answering directional questions and allowing them the time to provide more instruction. This better utilizes the budgetary needs of a library by providing work study positions to students while allowing the reference librarians to increase the number of classes they teach due to freeing up their time from staffing the desk. In addition to the budget benefits of employing students to assist with reference services, there are benefits to the librarians as well, such as improving their teaching skills by training PRCs who ask mindful questions which provide insight into how students learn and manage the research process (Faix, 
2014). This insight can be used by librarians to improve future explanations and examples while teaching classes of diverse students.

In the summer of July 2019, the PRC team drafted a PRC expectations document (Appendix 1) to clearly identify the duties of the PRCs. As other universities have their peer mentors doing a wide range of duties from wayfinding to providing reference services, the PRC team decided to set the bar high, knowing the CFL students hired would rise to the task. The document clarifies that PRCs will have three main responsibilities including staffing the desk, assisting with instruction, and conducting outreach. Outlining the duties for staffing the desk, the document states that PRC interactions with an individual student are expected to last roughly 30 minutes. If more time is needed to assist the student, a referral to a reference librarian should be made.

Since the PRCs already spent at least three semesters working in Access Services, they have a strong foundation in customer services skills and knowledge of required tasks in the library. Having three semesters of previous work in the library also allows for students to have taken the first reference training session addressing what most students are allowed to answer, as well as the advanced reference training session on what the Senior Students (those working nights and weekends) are allowed to answer. This training aids in their ability to understand the referral process and what questions might be beyond their skill set, along with knowing which subject librarian patrons should be referred to. As a PRC, their training includes refining topics, developing research questions, finding research articles, evaluating sources, and citation styles. After completing all research training materials, a PRC can then become a Lead PRC, capable of training the next PRCs hired. 
To decrease staff concerns, the team ensured the PRCs were both familiar with the RUSA guidelines and librarians were provided a modified checklist of these standards to note if the PRC met or did not meet the expectation, along with a column to denote if the standard did not apply. Roleplaying experiences before "going live" (either with a team member or recorded with a Lead PRC that was then forwarded to the team), were reviewed. This reinforced their use of guidelines such as open body language, a friendly greeting, smiling, asking if the question had been answered, and providing follow up options.

In addition, there were concerns from some reference librarians about the PRCs not conducting effective reference interviews. To alleviate concerns, the training program is designed to take several months, and the PRC team spends many training sessions emphasizing the importance of reference interviews and how to effectively conduct them. The PRCs, as former Senior Students in Access Services, already possessed demonstrated strength in the customer service aspects of the RUSA guidelines. Clark, Gabriel, and Borysewicz taught the PRCs foundational search competencies, and all the reference librarians extended that knowledge through frequent dialogue and modeling with structured activities and time set aside for formal debriefs. At these sessions, PRCs were able to demonstrate their competency as well as their interest to learn more from the subject specialists. Taking the time to hold these sessions before a PRC would be on their own was an important way to build trust and buy-in. It also helped ease the anxiety for librarians to know that the PRCs understand when it would be appropriate to refer the question to a reference librarian, such as for research questions from graduate students, instructors, or faculty. Concerns 
were allayed as a comfortable camaraderie and collaboration naturally developed when the PRCs worked with librarians in training, teaching classes, and creating instruction materials.

\section{Why it Works: Training/ History of Student Access Services Training}

As mentioned earlier, Access Services already had a successful training program in place that focused on Learning Outcomes (LOs), yearly evaluations, and ongoing discussions that worked to prepare student employees for work beyond college. Clark had been part of a campus initiative to develop LOs that could be standardized across UND departments and this was shared with all CFL employees. Reference staff were already familiar with the standards, but in working with the PRCs, they discovered how ingrained the behaviors had become and how the students could eloquently express how they were meeting the specific LOs.

The PRC team decided that only students currently working in the Public Services of CFL would be eligible to apply to the program. The authors believe that this decision makes it unique among other library PRC programs and has contributed enormously to the success of the program. The LOs of Access Services were based on skills outlined by NACE, the National Association of College and Educators (NACE, 2020), on what employers across the United States seek when hiring recent college graduates. These LOs provide soft skills in customer service, which became invaluable in making the nervous new PRCs still seem approachable and knowledgeable. Since these student employees are already experienced in providing customer service, the PRC team 
was confident the new mentors would be more approachable and have the confidence to assist other students with research.

Academic Brass published an article in 2015 stating that student workers giving reference assistance would need to troubleshoot common technology problems, locate physical and online resources, act as triage, and recognize when a query was too complex for them to handle. CFL night student employees (upper classmen) are already handling technology concerns and often do their best to assist patrons with locating the resources they need. These "seasoned students are better able to perform higher-level thinking than freshmen, making them better suited to provide reference service" (Faix, et al., 2010, p 96). In addition, there are several times during the day when Access Services student employees fill in for reference due to staffing shortages during meetings.

\section{Program Implementation}

There are several aspects which helped with the program's implementation, including the PRC Expectations Document (Appendix 2), a review of the literature on peer mentors, and talking to other librarians at universities with similar programs. Clark completed a literature review on peer mentors in academic libraries in 2016. In 2018, Gabriel was taking an Adult Learners class for her Graduate Certificate in College Teaching from UND and as a research project, completed an additional literature review on peer mentors, which also helped guide the program's implementation. In addition, several CFL librarians had visited GVSU in Michigan before CFL 
had considered creating a program, and when GVSU continually came up in the research, the PRC Team reached out to them for advice, as well as to several other libraries with PRC programs, including Coastal Carolina University and Southern Illinois University.

A small team of champions from Access Services and reference helped the project get off the ground and build support from coworkers. Keeping library leadership informed of the program's progress was essential. One challenge was making sure that all the reference librarians were informed about the stages of the PRC's training, as well as being aware of policies and procedures. For example, clearly stating when the PRCs would start answering phone, email, and chat reference questions in addition to helping face-to-face patrons is important. Clarifying how the on-call librarian would be reached in case a PRC needed support is necessary. Documented expectations are also needed for when PRCs are co-teaching English composition classes with a librarian.

\section{Hiring Process}

The hiring process and interviews for the PRC positions are conducted in a professional manner to better prepare students for job interviews upon graduation. While still a student position, the applicants are asked to include a professional resume and cover letter. A commitment of two years in the position was requested from candidates when the team developed its first cohort of PRCs. In the application process, candidates submit an essay detailing what they could bring to the position, as well as what they see as strengths and challenges in the library. This helps the 
team recognize students who are self-reflective, forward thinking, and have a desire to help their fellow students. The team decided that only those students currently working in the Public Services of CFL would be qualified to apply as the program was being developed, due to the strong basis in library knowledge already in place for these students.

\section{Job Description}

During the planning and development phase, before hiring, the abilities and work relationships that would be required need to be addressed. The job description includes the following items:

- Work both Fall and Spring semesters (Nine-month position).

- Be available during business hours, Monday through Friday.

- Attend regularly scheduled trainings with librarians and complete online tutorials.

- Provide peer reference assistance for undergraduate students in a variety of methods including face-to-face, email, telephone and online LibAnswers chat services.

- Assist librarians with information literacy instruction in classes and create materials such as research guides.

PRCs may work over the summer if they wish; however, this is not required. Working during business hours is required to ensure PRCs can meet with the team as they complete their assignments, that librarians are available to shadow on the desk, and that all PRCs have a dedicated time to meet. 


\section{Qualifications}

Expectations are high for the incoming PRCs, especially for the first few ones hired as they would help determine if the program would succeed. The qualifications are separated into required and preferred, which was a new detail for many of the undergraduates. Clark advises the students on how to best apply their current skill sets and use the "buzz words" that many employers are looking for in future application processes. Because of a potential bias, and because she is already closely associated with the students as their direct supervisor in Access Services, Clark relies on Gabriel and Borysewicz to make the final decision in the hiring process. Clark provides feedback on students' strengths and weaknesses, much as a reference call may do for other job candidates.

\section{Required Qualifications}

- Minimum of three semesters employment in Access Services

- Completed reference training session

- Resume, cover letter, class schedule

- Communication and customer service skills

- Critical thinking skills

- Understanding of referral process to reference librarians

- Collaboration

- Accountability 
- A written essay

With a focus on professionalism, and because it helps prepare students for careers beyond college, applicants are expected to write a resume and cover letter specific to the job they were applying for. Having students' class schedules for the next semester is a benefit in planning work schedules with minimal overlap on the service desk.

As noted previously, the applicants have at least 1.5 years, or three semesters, of public service training in the library. This provides PRCs with the basics of customer service, demonstrating an understanding of the culture of "yes" and "let me help / show you," along with a strong base in the LOs that the library prioritizes. Discussion in the literature highlights that if incoming freshman or students with no previous library experience are hired, additional steps would be needed to ensure an understanding of the library and the skills needed to successfully do the job.

Communication, demonstrated in writing and on the phone, must be marked on evaluations and through observed comments over an applicant's employment as professional, friendly and approachable. Related to the RUSA guidelines, this means that they are alert, demonstrating noninterruptive listening skills, paraphrasing and clarifying as needed, and articulating clear responses. This customer service skillset also includes providing direction, having negotiation skills, and the basic understanding of interview techniques (Dinkens \& Ryan, 2010). 
Clark encourages critical thinking from the first day a student begins working in Access Services. Encouraging students to think outside of the box and to ask questions are a primary focus as she prepares students to become leaders. Students are always welcome to question her reasoning and the way tasks are done, which leads to innovation and has helped the library become more efficient over the years. These creative and questioning students are needed to help develop the new PRC program and see it succeed. This has proven to be a key in being able to quickly solve problems and "think on their feet" when a student presented a reference question that a PRC did not know much about.

Accountability is measured again through student employee evaluations, as it is one of the LOs. Expectations are that they not only show up for work on time or let Clark know they cannot come in, but that they are also active in helping to complete training checklists for newer students. Students record their daily projects, accurately and consistently record library statistics on questions they were asked at the desk, and regularly check in with staff when working on projects together.

In addition, applicants are asked to write 500 to 1,000 words regarding their ideas for the library, how they use the library, and why they are interested in the position. The PRC team uses the essay to evaluate grammar and written communication skills. The essay also helps the team 
evaluate students' critical thinking skills and creativity as applicants discuss their ideas for the library and why they are interested in the position.

\section{Preferred Qualifications}

- Evaluation score of $35 / 40$

- Completed English 130 (English Composition)

- $\quad 3.0$ Grade Point Average (GPA)

The library student employee evaluation form has four categories of skill level ranging from novice to expert. When a student starts in Public Services, it is expected that their scores will be in the novice or developing levels. As mentioned earlier, there is no sense of failure. The novice category encompasses the fact that students are simply untrained. There are ten student items that are evaluated, meaning at their least skilled they would earn an evaluation of 10/40 (Clark \& Walker, 2017). If the students want to "level up" into the role of a Senior Student, Clark expects a minimum of $26-28$ on their evaluation. She is always clear with them that a perfect $40 / 40$ is a rare accomplishment, as learning is an ongoing activity. However, in the interest of improving themselves and having goals within the library, the PRC team agreed that 35 was an acceptable score that could be - and regularly is - attained due to the high standards that Clark sets for all student employees. 
One of the first hired PRCs had missed taking the English Composition class as he had transferred from another university. Because of situations like this, the team decided to leave this requirement in the "preferred" category, so as not to penalize highly skilled students who otherwise fit all the criteria. Likewise, the 3.0 GPA is not required as some students struggle due to learning difficulties, but they may excel in practical situations. To date, this has not been a concern for the team as everyone that has applied has held at least a 3.2 GPA. Some of the Access Services students have even commented that they feel part of the reason their grades have improved is due to skills learned while working in the library.

\section{Interview}

The students complete a professional one-hour interview (Appendix 1) to both encourage them to see this as a higher-level position and to help prepare them for professional interviews beyond college. Students are expected to dress professionally and prepare questions to ask the PRC team. Each of the applicants has shared that the interview was extremely nerve-wracking for them, but they felt they had learned a great deal from the experience. Senior Students are all provided opportunities to sit in on the interview process for new student hires for Access Services, and the PRCs mentioned that having had that opportunity helped them develop strong responses with detailed examples to possible interview questions. All felt more prepared for the questioning, and they mentioned it was the longest interview they had ever completed. Clark discussed with them after the interview that this is a standard in the "real world," as is having multiple interviewers in a room with an applicant. 


\section{Training}

Because students join the program with at least 1.5 years in CFL Public Service, they already know the basics of expected professionalism, customer service and the LOs used in evaluation processes. The LOs were developed as part of a campus wide initiative Clark was involved in (Clark \& Walker, 2017) to prepare students with the soft skills needed beyond college. CFL staff review this annually when NACE updates their lists. The chosen goals, focusing on soft skills in customer service, are accountability, approachability, communication (written and verbal), efficiency, knowledgeability, respect, and teamwork. These skills are ingrained by the point a student applies to become a PRC, having already demonstrated all of them to a high degree, as noted in the expectation of at least a 35 out of 40 on the evaluation form (Clark \& Walker, 2017, p. 226) which outlines these LOs.

The LOs also model essential skills for reference services following RUSA guidelines. Many libraries are utilizing similar outcomes for paraprofessionals assisting in reference, such as those which Pedzich (2000) noted:

- Approachability. This is demonstrated through body language, facial expression and eye contact, as well as portraying an open, friendly, and positive attitude to create rapport.

- Respect. Students need to keep confidences, remain neutral and non-judgmental, and know how to handle difficult patrons, while being sensitive and intuitive.

- Knowledgeability. Students must clearly know the policies, mission and values of the library, and what the guidelines are on when they may assist and when they must refer to 
a librarian. Persistence and creativity are needed to locate alternative resources (Dinkens \& Ryan, 2015).

- Accountability. Specific to UND's goals and like Coastal Carolina University (Faix et al., 2010), CFL staff know how conscientious their student workers are in working with minimal supervision and recording and completing tasks.

The first two PRCs were hired at the end of Spring semester 2019, with the intent to start them both in the fall. Fortunately, one was able to begin in the summer session, which allowed the pilot program for training to begin earlier than expected. This was instrumental in helping the PRC team determine what items worked well and what needed further clarification within the online training. The PRC was able to add to her resume that she was a co-developer on the training materials, as she would test, recommend changes or things that did not work, and retry. By the end of the summer, she was creating content to enhance the training materials.

With the goal of having Lead PRCs eventually guide the training of their fellow PRCs, this was implemented early in the Fall of 2019 when the second PRC started his training. In addition to an individual weekly meeting with the PRC team, the PRCs met for their own team time. The first hire was able to provide tips and tricks figured out over the summer to our new PRC, and this process also reinforced the training lessons she had previously completed. 
In the Spring of 2020, two more PRCs were hired. The two PRC Leads had a weekly meeting (team time), held Friday mornings, where they would discuss their week, including how they handled questions, what databases they utilized, and if they requested assistance from a librarian. Within just a few weeks, there was a sharp improvement in the way the new PRCs completed their training modules, which demonstrated that they had internalized the majority of information they were given by their peers and applied it to their own work.

In addition, each student is asked to keep a daily journal of how they are developing. This process allows the PRC team to note areas of weakness in the program, as well as address concerns or confusion for the PRC by their next work shift. After PRCs complete the training, they are required to complete a weekly journal entry rather than a daily entry. This process allows the team to remain up to date on what the PRC is experiencing or feeling regarding their duties and challenges.

The training concept was adopted from the Robert L. Turchin Library (Tulane University) and duPont-Ball Library (Stetson University), which recommends the development of an online program in which students can work at their own pace to learn about customer service, diversity issues, the code of ethics, and safety practices (Dinkens \& Ryan, 2015). For CFL training, this is a combination of an online research guide and team time with librarians to review PRC's work. The guide familiarizes PRCs with the ALA Bill of Rights and the RUSA guidelines expected of reference librarians. From there, PRCs are asked to consider a time they have been given both good and bad service from a librarian and how that made them feel. This provides them with a 
basis on remembering that sensation of success or failure to better serve their peers in the future. Next, PRCs use a broad topic provided to them and find multiple resources including definitions, research, biographies, and more. This is done before they are given any "official" training, and this helps to reinforce the sense of "getting lost" in the research path, as well as providing them the first tools they would need (such as subject terms, the thesaurus function in databases, and the use of Google Scholar). Debriefing at the end of each assignment with the PRC team about each PRC's search results reinforced the research process.

This PRC training is scaffolded, allowing each lesson to add to their own knowledge base. While conducting a reference interview, they are asked to review the RUSA guidelines, as well as a shortened list that is used to evaluate their reference transaction. The evaluation focuses on physical and verbal approachability and interest (standing up, asking how they can help, and making eye contact). They are then evaluated on listening without interrupting and inquiring with open-ended questions to clarify the need before showing the student the appropriate research guides or databases. Follow up includes verifying the student understood the search path and asking if they had enough information to start, as well as providing the subject librarian's card.

Using a template Clark was given during her own MLIS training, the PRCs then write down both sides of the conversation, acting as PRC and as the patron. Clark then meets with each PRC to review wording, neutrality, clarification, and ensuring they were not promising things that cannot be given or completed. This process is done two to three times, then they pair with a Lead PRC 
to use CFL's One Button Studio recording room to video a role play interaction. The Lead PRC provides a question and the new PRC applies their interview skills. At this point, the PRC team is not looking for PRCs to find the ideal resource, but instead to show that PRCs understand the importance of RUSA guidelines.

Repeatedly, students are encouraged to struggle through this process. However, steady and timely feedback is integral to their training. Coaching to address both their strengths and weaknesses helps make them stronger researchers. An integral part of this evaluation process is to never address missteps as a failure on their part. Instead, the coaching is presented as a reminder of "this is what your peer may be feeling or experiencing as well. How will you help them?" Praise and encouragement at every step builds their confidence to continue to follow procedures (Borin, 2001).

Once the PRC team has reviewed this assignment, the PRCs move on to a list of five commonly asked questions in each subject librarian's areas. Once complete, the subject librarian is invited to come to the team meeting and review the content with the PRC. This process has been good not only for the students, but for the entire PRC team. The librarians have all learned a great deal in how others approach research and gained greater understanding of databases they may not regularly use themselves. This has been so well-received that Clark was even asked by two other departments in the library that utilize librarians if they could use parts of the research guide for training new full time hires in their own areas. Additionally, PRCs document their work answering questions using concept maps, permalinks, and written descriptions for typical subject 
questions. The documentation and discussion help create stronger acceptance of the ability of undergraduates to both effectively do research and explain how they researched a topic. This training process creates a better team environment for the PRCs and the whole reference department.

Roughly four to six weeks after starting the training, PRCs begin shadowing in the English Composition classes. The first few times, they only listen and then later assist in answering questions during the hands-on portion of the class. Discussing those experiences in team time provides PRCs the opportunity to reinforce the reference interview process and improve their instruction skills. The PRCs immensely enjoy the teaching - more than they expected - and within a few sessions, the PRCs were teaching modules within the session, with the librarian on hand as needed. All PRCs have mentioned that the combination of the training process and the ability to help teach the English Composition classes has made them better researchers themselves.

In conjunction with the English Composition classes, PRCs started shadowing reference librarians on the Ask Us desk where they answered questions face-to-face, as well as by email, phone, and chat. Like the English Composition classes, PRCs watched and observed many times before stepping in to answer a question themselves. When they were ready (three to five weeks, depending on the number of shifts worked), the PRC took the lead in assisting patrons while the librarian worked at the secondary desk to be on hand for support. Each time, the librarian would review afterwards why they did what they did and why they chose specific databases. This model 
of read, practice, observe modeled behaviors, and "go live" are standards of Clark's training in Access Services as well (Clark \& Walker, 2017). She has found that providing multiple methods for students to learn, often leads to stronger retention, greater confidence, and higher skill in what the students are accomplishing.

Because the subject librarians used to have reference department student assistants to aid in updating research guides, PRCs are given their own "sandbox" guide to experiment at about the same time as they start shadowing the librarians on the Ask Us desk. This allows the PRCs to play with different styles; many of them use it to organize information and elements of what they are learning in their training. This way, before working on a live guide for a subject librarian, PRCs can investigate and ask questions on how things work on the platform.

\section{Marketing and Outreach}

There are several ways, both formal and informal, that CFL market the program to the campus community. Changing the image of the reference desk began by rebranding it from "Ask a Librarian" to "Ask Us" to make the shared work area more inclusive of student involvement. While all students wear a lanyard, the PRCs are provided a professional name tag similar to the full-time staff, theirs saying Peer Research Consultant. They are also asked to share news of the program with classmates and professors, as well as follow a dress code of black shirts so they can be easily recognized. This dress code was relaxed slightly during Fall 2019. The second PRC that had started worked a few hours every day and had multiple classes with the same professor. 
The professor finally asked him why he was wearing black every day. When the PRC team heard about this, discussion followed on how it was noticeable and provided an opportunity for the PRC to talk about his role. The challenge was, on speaking with the PRC, it limited his wardrobe and required more laundry. The dress code was expanded to include black, UND colors or UND branded clothing.

Marketing also includes social media postings to our UND Today campus blog and CFL's blog. Student marketing employees develop promotional items in a variety of formats including print posters, digital displays, and postings on Twitter, Facebook, and Instagram. Student involvement in marketing efforts is essential because students oft en know the most effective way to engage with their peers in an online format. The PRCs are each asked to come up with a 30-second and a one-minute pitch they can use to quickly explain the PRC program to others. In Fall 2020, CFL student marketing employees will advertise the Knowledge Commons using social media, campus digital signs, print flyers on campus bulletin boards, while the PRCs share information to English Composition instruction sessions and other targeted undergraduate classes.

\section{Lessons Learned}

Many of our lessons learned are related to communication between the PRC and reference staff. One aspect which helped us grow as a team was having the individual reference librarians meet one-on-one with each PRC to discuss 5-6 typical reference questions. This is also a time when 
reference librarians can share information about their other job duties to build a stronger team relationship.

The PRC team keeps a diary of training for each student, which is not viewed by the students because it is for organizational purposes only. The diary contains several columns including date, names of individuals present, time spent, description of training activities, method (face-to-face, email, or online), action steps, and learning outcomes addressed in the training. This training diary is also helpful to track how much time the PRC team is spending training the PRCs. It also keeps all three team members aware of progress if they are unable to attend any of the meetings.

It was determined to be very helpful to have new PRCs complete their training assignments and tutorials away from the service desk for their first 4-6 weeks so that they could focus and not be interrupted by patrons coming to the desk for help. The PRC librarian team stayed at three members, but did bring in other librarians for specialized instruction as needed, such as specific subject databases used only for certain disciplines.

The first year of developing and implementing the PRC program was a heavy time commitment for the PRC team to develop the training guide and communicate policies to other library staff. The first semester required the strongest time commitment. Second semester eased a little with a Lead PRC to assist in some of the training. By the third semester, having two strong Lead PRCs allowed the reference librarians to step back a little as a PRC team time fell into place every 
week where the students can share weekly challenges and best practices. PRC Librarian Clark continues to be present as a mentor for these meetings, but she lets them lead following an agenda they developed which consists of librarian updates, their weekly experiences, and having the new PRCs share their challenges and questions. The meetings end with a demonstration of something the Lead PRCs enjoy about the job, such as navigating a particular database.

\section{Next Steps}

The PRC Team is utilizing Microsoft Teams for communication, project management, and file sharing. Two additional PRCs will be hired for Fall 2020 and the Lead PRCs will take more responsibility for training them. The Knowledge Commons will also open in the library at this time. This area is modeled on what other universities have implemented by bringing in academic partners. Their undergraduate mentors will work in a dedicated area alongside CFL's PRCs to assist their peers. While discussions are still being finalized with some partners, Career Services and the Writing Center have currently committed to joining the area to assist in matters such as resumes and papers.

Challenges still faced in getting the Knowledge Commons staffed and utilized involve both hours and privacy. This area should be dependably staffed, yet doing so depends on the class schedules and availability of student hours. This staffing will be resolved as a full team of PRCs are trained over the next few years. There are adequate desk corrals for all partners to be present at the same time. However, as the Director of the Writing Center on campus emphasized, there is 
also a level of privacy for students' needs that should be addressed. Students often need privacy to concentrate without distractions, and this area is front and center at the hub of CFL's main floor, directly located by the stairs and elevators. In addition, privacy is important because students may still see a stigma attached to seeking assistance and may choose not to approach a very public location.

At the end of the first academic year utilizing PRCs, assessment is still in the developmental stage. Due to COVID-19, the library staff began to work from home in March of 2020. The COVID-19 pandemic slowed the ability of the most recently hired PRCs to finish their training and to fully implement all PRCs in the Knowledge Commons as had been planned for after the university's spring break. Without the ability to have the newest PRCs assist in composition classes or be staffing the desk, it has been difficult to assess the continued viability of the program and methodology beyond observation and hearsay. The PRC team continues to collect information in the diary and verifies that learning outcomes are being met. Official evaluations of the PRCs will take place at the end of the first semester back in the physical building.

Fortunately, one PRC has been able to continue working over the 2020 summer semester to assist librarians in preparing for phased re-opening during COVID-19. CFL has experienced the increased stress, cumbersome logistics and staffing furloughs common for academic libraries in this time, yet has reaped immediate benefits from the PRC program. The PRC has been instrumental in moving most instruction to an online format, in developing online tutorials, and conducting online research appointment with students. Additionally, the PRC is involved in 
discussions on how to keep our frontline student employees and the patrons they assist safe during face-to-face interactions in the Fall of 2020.

\section{What You Can Do at Your Library}

For libraries looking to develop and implement a peer mentoring program, there are a few things the authors would like others to consider. Before advertising or hiring for peer researchers:

- Have a clear vision of what you want the PRCs to be doing before searching for applicants.

- Will they only be sitting at a desk providing directional support? If so, that could be assigned to a public service student. If the student will be providing reference and research assistance, how much will be allowed? What other tasks will they be given? Where will they sit to differentiate them from other students?

- Develop a job description.

- Hold the students to the same expectations as staff in this process. Write the job description with the required and preferred qualifications that clearly demonstrate what will be expected of them.

- How will they be assessed? (surveys from patrons, self-reporting, log sheets, etc.?)

- Administrators will need a measurement tool to verify if the program is a success. CFL uses a combination of answered questions recorded in a database, yearly evaluation forms, and visuals that are reported at weekly meetings. For example, there were several times where the librarian that was "buddied" with the PRC in 
training had to step away from the desk. The librarian returned to see a line of students queued up to receive help from a peer rather than a librarian.

- Will the students be paid higher? Will they bump into a higher pay bracket? Can you justify the higher pay? How will you pay for it?

- While not always an option to pay higher wages, this should be considered if possible. Students at CFL view this as part of the "leveling up" or promotion aspect of their time at the library. In the "real world" they would be expected to apply for better jobs; this is the same idea.

- Salary justification is detailed in the job description. Are they doing advanced work? Or are they nothing more than an Information Desk? If the latter, then no.

- For funding, explore options with partners and those that support the library and its services. A one-time payment is discouraged as the program is intended to carry on.

- Secure buy-in from your stakeholders - especially the President / Provost.

- If the first four items on this list are addressed, administration can view the request as something with merit and value. Align your program with institutional mission, campus climate and environment, and campus practice.

- The hardest buy-in may be those on the ground - the other librarians. Consider the benefits as listed in this paper to assist librarians in their tasks as well as putting the librarians out into the classrooms (physically or online) to complete teaching that is necessary for student success in research skills.

O Outside of the PRC Team, the reference team learned the value of the PRCs and has come to rely on them in both the English Composition classes and for their 
assistance on research guides and compiling information and data. The PRCs do in fact have a place at the desk and have allayed the concerns about only those with an MLIS assisting others in research. William Heinlen (California State University at Fresno) said in 1976: "The notion that student assistants have no place in academic reference is a spurious inflation of the professional ego" (White, 1985, p 95).

- Place the service and PRCs in a highly visible location.

O The first instinct may be to put a PRC at a lower desk, behind a librarian, or in an out of the way location, especially as buy-in is being built with the librarians. Avoid this at all costs. At CFL, the students are front-and-center where their classmates can see them. This has led to students approaching, not just to ask a reference question, but to find out more about the program.

- Be aware that program development will take time.

- CFL started developing the program in the spring of 2019. The first PRC trained that summer, then started the fall with shadowing at the desk. It was not until October that she was solely staffing the Ask Us desk and assisting in the classroom instructions.

\section{Conclusion}

Knowing the values and mission for your library helps determine the focus of the peer mentoring program. At CFL, the learning outcomes are focused on the skills that employers want to see in their employees including research, oral and written communication, leadership, interpersonal 
communication, conflict management, and critical thinking skills. Giving library student employees increased responsibility will not only increase their career skills, it will also provide the opportunity to increase students' pride in their work. When student workers are excited to come to work and share what they are accomplishing with the staff and their supervisors, their energy and enthusiasm is contagious for all library staff and has the potential to increase staff morale.

Programs around the country vary in what tasks they assign to their PRCs or mentors. CFL found that many of those tasks were already assigned to Access Services students, such as the basic reference search for a book, printing questions, or how to navigate the building. Taking this to the next level has been instrumental to the PRC's personal research skills as well as with peer to peer engagement with the university's undergraduate populace, aligning to the university's strategic plan. By creating a method of triage, where students at the Information Desk handle the directional and technical questions, reference questions are passed to the PRCs, and the difficult or time-intensive reference questions passed from PRC to reference librarians, CFL has created a unique program that has improved the ability of the librarians to focus on information literacy instruction and develop deeper connections with faculty in specific disciplines with the goal of aligning course assignments and student learning outcomes with appropriate library resources.

While a large, daunting prospect to create such a program from the ground up, the PRC team had buy-in and strong support from both library administration and campus leaders. One of the greatest opportunities afforded to librarians due to the program is the ability to conduct more 
outreach and training sessions across campus classes. Admittedly, the training is a time commitment that seemed overwhelming as the process began. Having a dedicated librarian focused on making a PRC program function is vital for at least the first year, both in developing training materials, working one-on-one with the PRC, and creating evaluative materials. By the second year, the Lead PRCs start taking ownership in the project.

CFL recommends starting with a successful student training program before jumping into a PRC program such as this. Make certain clear expectations, duties, and training are laid out with some method of a checklist for both the general student training and the PRC training. By the completion of their training, the first two PRCs have both conveyed through self-evaluation a rise in their professionalism and research capabilities by assisting others, which the PRC team has also noticed. This is consistent with findings at other libraries such as Kimbel Library at Coastal Carolina University where student researchers reported improvement in their research skills as well (Faix, 2014). The PRCs regularly express their pride in the trust and responsibilities placed on them, not only because they are the first group at this university library provided with the opportunity to assist librarians with research appointments, but also because they have the ability to speak to the librarians with the voice of student perspectives.

The authors are available to share other tips, challenges, and lessons learned, as well as to share their unpublished graduate research projects. The link to the Peer Research Consultants training guide is available online at https://libguides.und.edu/prc_training. This guide is constantly evolving as improvements are made to the training materials. 


\section{Bibliography}

Bandyopadhyay, A. \& Boyd-Byrnes, M. (2016). Is the need for mediated reference service in academic libraries fading away in the digital environment? Reference Services Review, 44(4), 596-626. doi: 10.1108/RSR-02-2016-0012

Bodemer, B. B. (2014). "They can and they should: Undergraduates providing peer reference and instruction." College \& Research Libraries 75 (2), 162- 178. Retrieved from: http://crl.acrl.org

Borin, J. (2001). Training, Supervising, and Evaluating Student Information Assistants. Reference Librarian 72, 195-206.

Borysewicz, K., Clark, K. T., \& Gabriel, H. M. (2019). PRC White Paper. Unpublished manuscript.

Bunnett, B., Boehme, A., Hardin, S., Arvin, S., Evans, K., Huey, P., \& LaBella, C. (2016). Where did the reference desk go? Transforming staff and space to meet user needs. Journal of Access Services, 13(2), 66-79.

Chester Fritz Library. (n.d.). Chester Fritz Library Strategic Plan 2018-2023. https://library.und.edu/about/_files/docs/cfl-strategic-plan2019.pdf

Clark, K.T. \& Walker, S.R. (2017). No more "magic aprons": Longitudinal assessment and continual improvement of customer service at the University of North Dakota libraries. 
Journal of Access Services, 14(4), 215-227.

https://doi.org/10.1080/15367967.2017.1392865

Dinkens, D. \& Ryan, S.M. (2010). Measuring referrals: The use of paraprofessionals at the reference desk. The Journal of Academic Librarianship, 36 (4), 279-286.

Evans, G. E., \& Alire, C. (2013). Management basics for information professionals (3rd ed.). New York, NY: ALA Neal-Schuman.

Faix, A. (2014). Peer reference revisited: Evolution of a peer-reference model. Reference Services Review, 42(2), p 305-319. DOI:10.1108/RSR-07-2013-0039

Faix, A. I., Bates, M. H., Hartman, L. A., Hughes, J. H., Schacher, C. N., Elliot, B. J., \& Woods, A. D. (2010). Peer reference redefined: New uses for undergraduate students. Reference Services Review, 38(1), p 90-107.

Lipson, S. K. \& Eisenberg, D. (2018). Mental health and academic attitudes and expectations in university populations: results from the healthy minds study. Journal of Mental Health, 27(3), 205-213. DOI: 10.1080/09638237.2017.1417567

Macy, K.V. (2015). Implementing online training and assessment to support peer reference in a business library. Academic BRASS, 10 (2). Retrieved from: http://www.ala.org/rusa/sites/ala.org.rusa/files/content/sections/brass/Publications/Acad_B $\underline{\text { RASS/2015 fall_macy.pdf }}$

NACE. (2020). Career readiness defined. National Association of College and Educators. https://www.naceweb.org/career-readiness/competencies/career-readiness-defined/ 
O’Kelly, M., Garrison, J., Merry, B. \& Torreano, J. (2015). Building a peer-learning service for students in an academic library. Libraries and the Academy, 15(1), 163-182.

Pedzich, J. (2000). Paraprofessionals at the reference desk: Training and Documentation. Legal Reference Services Quarterly, 18(2), 91-99.

Reiter, L. \& Cole, C. (2019). Beyond face value: Evaluating research consultations from the student perspective. Reference \& User Services Quarterly, 59(1), 23-30.

Ryan, S. M. (2008). Reference transactions analysis: The cost-effectiveness of staffing a traditional academic reference desk. The Journal of Academic Librarianship (34) 5, 389399.

University of North Dakota. (n.d.). One UND Strategic Plan. https://und.edu/about/mission/strategic-plan.html

White, E. C. (1985). Student assistants in academic libraries: From reluctance to reliance. The Journal of Academic Librarianship, 11(2), 93-97. 


\section{Appendix 1:}

PRC Interview Questions:

1. Give an example of a time when you used your fact-finding skills to gain information needed to solve a problem; then tell me how you analyzed the information and came to a decision.

2. Have you ever given instructions to someone, and then learned they did it wrong? What happened?

3. Have you ever had to get a point across to different types of people? What approach did you take?

4. Have you ever had an occasion when you misunderstood someone else's instructions? Why do you think that happened?

5. Describe a work or community experience in which you worked with people from different backgrounds. What was most challenging about the experience? What was most rewarding?

6. Tell me about a time you had to surmount an obstacle to reach a goal. What was the problem, and how did you handle it?

7. On what occasions did you feel you had to consult with your boss before proceeding with some action? When did you feel it was proper to act on your own?

8. It's possible, of course, to be loyal to your employer but still disagree with some rules and policies. Can you cite an example in your own experience?

9. How do you like to be managed? What are your expectations of your supervisor?

10. Describe a situation when you had to manage multiple priorities with limited time. How did you handle it? How did you decide what came first? 
11. What personal performance standards do you set for yourself? What have you done to meet them? What do you do if you find yourself falling short of a standard?

12. Tell me about a situation where you were a member of a team. What was your role and how did it make the teamwork more effective?

13. What did you do in your last job to contribute toward a teamwork environment? Be specific.

14. Do you have a philosophy of public service? How would you characterize it?

15. What do you see as the opportunities and challenges of this position?

16. Is there a question that we didn't ask for which you had prepared an answer or is there something you'd like us to know that perhaps we did not ask?

\section{Appendix 2}

\section{Peer Research Consultants (PRC) Expectations for Chester Fritz Library}

Peer Research Consultants (PRCs) will staff the desk, assist with instruction, and conduct outreach.

\section{Staff the Desk}

In Fall 2019, PRCs will staff the desk alongside a reference librarian. PRCs will answer questions face-to-face, as well as by email, phone, and chat. After about a month of training and shadowing librarians, the PRC will take the lead in assisting patrons who approach the desk. The librarian at the desk will provide support, as needed. If the patron is a graduate student (masters or doctoral), instructor, or faculty, the librarian will take the lead. 
PRC's interactions with an individual student are expected to last roughly 30 minutes, with a maximum limit of 50 minutes. At that point, if more help is needed, a referral to a reference librarian will be made.

PRCs will assist students with tasks such as:

- refining topics

- developing research questions

- finding research articles and resources

- evaluating sources

- citation styles

In Fall 2020, PRCs will be staffing the Knowledge Commons and answering a wide variety of questions. Karlene will provide support, and referrals to the subject librarians will be made. Holly and Kristen will assist with the training and assessment for reference, research and instruction skills. The Research Skill Development Framework as well as other professional library standards will be used as a basis.

PRCs will enter detailed information into LibStats or Springshare LibCRM, which will be reviewed weekly by Karlene and the PRC Team. PRCs will also write a reflection (with prompts 
from the PRC Team) at the end of their desk shift to reflect on what they learned, what they would do differently, and any comments about the shift. These reflections will be reviewed by Karlene and the PRC Team to adjust and improve training, as needed.

\section{Instruction}

PRCs will be active assistants in English 130 classes by introducing themselves at the beginning of class and giving a short description of the PRC program. PRCs will help with the hands-on portion of the class by assisting students with refining topics, finding keywords, database searching, citations, etc. At the discretion of the coordinator of research skills instruction, the PRCs may be asked to teach/demonstrate material for a class. PRCs will create and update research guides and other resources used for library instruction.

After assisting with an ENG 130 session, PRCs will write a short reflection on the event including what they learned and what they might do differently next time, which will be shared with the PRC Team to adapt and improve training as needed.

\section{Outreach}

1. Informally, PRCs will share news about the PRC service with their classmates and friends.

2. Formally, in Fall 2019, PRCs and our marketing student employee will advertise the PRC program to campus 
3. Formally, in Fall 2020, PRCs will advertise the Knowledge Commons using social media, campus digital signs, print flyers on campus bulletin boards, and information to English 130 instructions and other targeted undergraduate classes.

\section{Other Possible Duties}

- Develop training tutorials for future PRCs

- Assist at campus-wide new student orientation, move-in weekend events, de-stress events, and other campus outreach events

- Provide training to other CFL student employees, such as CFL orientation and reference training for Senior Access student employees

- Assist with curriculum mapping

- Assist with analysis of library instruction assessment data

- Assist at CFL citation management clinics

Things for us to consider:

1. PRCs will be proactive in directing students to the appropriate subject librarian using tools such as Springshare LibCRM, Starfish, email, and chat as appropriate. The PRCs may also direct students to our research guides as well as hand out our business cards to make the connection to a librarian.

2. Re-brand the Ask a Librarian Desk in Fall 2019 to the Ask Us Desk.

3. Best practices for creating connection and contact between PRCs and all the reference librarians: 
- PRCs are invited to library events, such as an open forum for new professional librarian position candidates.

- Workshops where PRCs and all librarians attend

- PRCs will shadow each librarian to informally create better ties

Goals of PRC program

- To contribute to student learning by leveraging the social advantages of peer learning

- To enhance the learning and collegiate experience of the students hired by CFL

- PRCs will practice the skills of facilitation, oral communication, problem-solving, customer service, and reference interview skills to develop career readiness.

- Contribute to UND's Strategic Plan by providing High Impact Practices (HIPs) to the undergraduates working as PRCs.

Team buy-in when PRCs assist in ENG 130 sessions:

- Commitment to having PRCs as valued partners in the classroom and using the Eng130 lesson plan as developed.

- Encouraging PRCs to assist students during the hands-on portions and perform teaching demonstrations when appropriate.

- Must communicate shared expectations to the entire team.

- Shared understanding of how to give constructive feedback to PRCs.

End of the semester, self-reflection questions for PRCs:

- This semester as a PRC, I learned... 
- $\quad$ Being a PRC helps me succeed at UND because...

- The PRCs contribute to UND campus life by...

- One example of how I was able to help a student this semester is (include the information need and how I helped meet that need...)

- The PRC Program could be improved by...

Created by Kristen Borysewicz, Karlene Clark, and Holly Gabriel, July 2019 